Pengaruh Latihan Stride Jump Crossover Dan Latihan Single Leg Stride Jump Terhadap Power Otot Tungkai Atlet Bola Voli Putri Johar VC Deli Serdang Tahun 2020

\title{
Pengaruh Latihan Stride Jump Crossover Dan Latihan Single Leg Stride Jump Terhadap Power Otot Tungkai Atlet Bola Voli Putri Johar VC Deli Serdang Tahun 2020
}

\section{The Effect of Stride Jump Crossover Exercise and Single Leg Stride Jump Exercise on Leg Muscle Power of Volleyball Athletes Johar VC Deli Serdang in 2020}

\author{
Putra Oka Harahap ${ }^{1}$ Novita $^{2}$ \\ ${ }^{1,2}$ Fakultas Ilmu Keolahragaan, Universitas Negeri Medan \\ Email: putraokahrp@gmail.com
}

\begin{abstract}
ABSTRAK
Penelitian ini bertujuan untuk mengetahui pengaruh latihan Stride Jump Crossover dan Latihan Single leg Stride Jump terhadap Power otot tungkai pada atlet bola voli Putri Johar VC Deli Serdang Tahun 2020,latihan Stride jump Crossover dan latihan single leg stride jump merupakan latihan yang dapat membantu menigkatkan power otot tungkai pada permainan bola voli dan dalam latihan nya bermain dengan set dan repetisi yang di ukur melalui intensitas latihan. Metode penelitian adalah Eksperimen dengan waktu penelitian selama 6 minggu dengan latihan selama 3 kali latihan dalam seminggu, jumlah sampel yaitu dengan total sampling sebanyak 10 atlet, semua sampel melakukan bentuk latihan yang telah disusun dalam program latihan dan melakukan pre test sebelum latihan diminggu awal dan post test setelah akhir latihan di minggu terakhir. Analisis hipotesis yaitu, pengaruh latihan Stride Jump Crossover dan latihan Single Leg Stride Jump terhadap power otot tungkai pada atlet bola voli putri Johar VC Deli Serdang Tahun 2020, diperoleh $\mathrm{t}_{\text {-hitung }} 4,39$ dan $\mathrm{t}_{\text {tabel }} 2,26$ pada taraf nyata $\alpha=0,05$ maka t-hitung > t-tabel. Berdasarkan kriteria pengujian hipotesis yaitu $\mathrm{H}_{\mathrm{O}}$ ditolak dan $\mathrm{H}_{\mathrm{a}}$ diterima, maka dalam penelitian ini menyatakan bahwa "terdapat pengaruh latihan Stride Jump Crossover dan latihan Single Leg Stride Jump terhadap Power otot tungkai pada atlet bola voli putri Johar VC Deli Serdang Tahun 2020.
\end{abstract}

Kata kunci : Stride Jump Crossover, Single Leg Stride Jump, Power Otot Tungkai

\begin{abstract}
This study aims to determine the effect of Stride Jump Crossover and Single leg Stride Jump training on leg muscle power in volleyball athletes Putri Johar VC Deli Serdang in 2020, Stride jump crossover training and single leg stride jump exercises are exercises that can help increase muscle power. limbs in volleyball and in training play with sets and reps as measured by the intensity of the exercise. The research method is an experiment with a research time of 6 weeks with training for 3 times a week, the number of samples is a total sampling of 10 athletes, all samples do a form of exercise that has been arranged in an exercise program and do a pre-test before training in the initial week and post. test after the end of the workout in the last week. Hypothesis analysis, namely, the effect of Stride Jump Crossover training and Single Leg Stride Jump exercise on leg muscle power in female volleyball athletes Johar VC Deli Serdang in 2020, obtained t-count 4.39 and t-table 2.26 at the real level $\alpha=0,05$ then $\mathrm{t}$-count $>\mathrm{t}$-table. Based on the criteria for testing the hypothesis, namely $\mathrm{HO}$ is rejected and Ha is accepted, this study states that "there is an effect of Stride Jump Crossover training and Single Leg Stride Jump training on leg muscle power in female volleyball athlete Johar VC Deli Serdang in 2020.
\end{abstract}

Keywords: Stride Jump Crossover, Single Leg Stride Jump, Leg Muscle Power 
Pengaruh Latihan Stride Jump Crossover Dan Latihan Single Leg Stride Jump Terhadap Power Otot Tungkai Atlet Bola Voli Putri Johar VC Deli Serdang Tahun 2020

\section{PENDAHULUAN}

Menurut UU RI No 3 (2005)

Olahraga merupakan sebagian dari aktivitas sehari-hari yang berguna untuk membentuk jasmani dan rohani yang sehat. Sampai saat ini olahraga banyak memberikan dampak yang positif dan nyata bagi kesehatan terkhusus untuk masyarakat. Banyak manfaat yang di peroleh langsung dari aktivitas olahraga tersebut baik untuk anakanak sampai orang dewasa. Pada perkembangannya olahraga terbagi menjadi 3 jenis olahraga yaitu olahraga prestasi, olahraga rekreasi dan olahraga pendidikan.

Olahraga prestasi adalah olahraga yang membina dan mengembangkan olahragawan secara terencana, berjenjang, dan kelanjutan melalui kompetisi untuk mencapai prestasi (Arif, Y., \& Alexander, X. F. R., 2019). Salah satu cabang olahraga yang menjadi olahraga prestasi yang sudah dikembangkan dan sudah profesional adalah olahraga bola voli (Roziandy, M., \& Budiwanto, S., 2020). Hal tersebut dilatih secara sistematis agar kemampuan bermain bola voli semakin baik.

Permainan bola voli adalah olahraga yang dimainkan oleh dua tim dalam setiap lapangan dipisahkan oleh sebuah net". Tujuan dari permainan bola voli adalah melewatkan bola dari atas net agar dapat menyentuh lantai lapangan lawan dan untuk mencegah usaha yang sama dari lawan. Setiap tim dapat memainkan tiga pantulan untuk mengembalikan bola. Tim yang memenangkan sebuah reli memperoleh satu angka dan berhak untuk melakukan service, serta para pemainnya melakukan pergerekan satu posisi satu arah jarum jam.

$$
\text { Menurut Mukholid }
$$

Mengemukakan teknik permainan bola voli terdiri dari : service, passing, smash, block. Dalam permainan bola voli terdapat faktor yang menunjang dalam pencapaian prestasi antara lain adalah fisik. Penguasaan fisik dalam permainan bola voli merupakan salah satu unsur yang ikut menentukan menang kalahnya suatu pertandingan. Dari sekian banyak faktor-faktor yang ada, fisik merupakan faktor yang sangat penting dalam melompat dengan setinggi-tingginya untuk menyerang atau dalam melakukan teknik teknik dalam bola voli untuk meraih kemenangan.

$$
\text { Menurut Sajoto }
$$

menyatakan bahwa "kemampuan fisik merupakan salah satu persyaratan yang sangat diperlukan untuk meningkatkan prestasi seorang atlet guna mendukung perkembangan teknik, taktik, strategi, dan kemampuan mental individu atlet". 
Pengaruh Latihan Stride Jump Crossover Dan Latihan Single Leg Stride Jump Terhadap Power Otot Tungkai Atlet Bola Voli Putri Johar VC Deli Serdang Tahun 2020

Permainan bola voli mengacu kepada kemampuan fisik untuk meningkatkan peforma atlet dalam permainan bola voli, semestinya atlet perlu mendapat perhatian serius dalam usaha pengembangan dan peningkatan kualitas fisik.

Dalam permainan bola voli terdapat faktor yang menunjang dalam pencapaian prestasi antara lain adalah fisik. Penguasaan fisik dalam permainan bola voli merupakan salah satu unsur yang ikut menentukan menang kalahnya suatu pertandingan (Arrahman, Z., 2017). Dari sekian banyak faktor-faktor yang ada, fisik merupakan faktor yang sangat penting dalam melompat dengan setinggi-tingginya untuk menyerang atau dalam melakukan teknik teknik dalam bola voli untuk meraih kemenangan (Oktaviani, S. M., 2020). Karena permainan bola voli merupakan permainan cepat maka faktor fisik (power otot tungkai) sangat penting dalam melakukan teknik teknik untuk menyerang.

Fungsi power otot tungkai dalam permainan bola voli ini ialah tindakan nya untuk melompat setinggi-tingginya dalam melakukan tenkik-teknik untuk penyerangan dalam bola voli sehingga mampu menghasilkan teknik-teknik yang baik dalam bola voli (Mubarrok, M., \& Adi, S., 2017). Hal itu dapat dilihat bahwa lompatan dalam teknik-teknik bola voli. Semua sikap dalam melompat bisa dilakukan untuk melakukan smash maupun melakukan blok dalam penyerangan maupun pertahanan dalam permainan bola voli.

\section{METODE}

Metode yang digunakan adalah Metode Eksperimen dengen teknik pengumpulan data menggunakan Pre-test dan Post-test (Hidayat, T., Saichudin, S., \& Kinanti, R. G., 2018). Adapun pelaksanaan penelitian ini adalah mengambil data pretest (hasil power otot tungkai) dan memberikan perlakuan (Treatmen), berupa latihan (stride jump crossover dan single leg stride jump) terhadap subject pada waktu tertentu, dan di akhiri dengan perlakuan post-test (hasil power otot tungkai) dilakukan sebelum dan sesudah perlakuan dilakukan. Adapun tempat pemgambilan data dilaksanakan di lapangan bola voli Johar VC J1. Pasar VI Desa Pematang Johar, Percut Sei Tuan, Deli Serdang. Penelitian ini dilaksanakan 18 kali selama 6 minggu dengan persentase latihan 3 kali dalam seminggu.

Populasi dalam penelitian ini adalah semua atlet bola voli johar vc deli serdang dengan jumlah 10 orang dan sampel 10 orang. Teknik pengambilan sampel menggunakan teknik purposive sampling 
Pengaruh Latihan Stride Jump Crossover Dan Latihan Single Leg Stride Jump Terhadap Power Otot Tungkai Atlet Bola Voli Putri Johar VC Deli Serdang Tahun 2020

(sampel bertujuan). Tujuan penelitian ini adalah Untuk mengetahui ada tidaknya pengaruh latihan stride jump crossover dan latihan single leg stride jump terhadap peningkatan power otot tungkai pada atlet bola voli putri Johar VC Deli Serdang tahun 2020.

Adapun prosedur penelitian ini adalah 1) Mengambil sampel sebanyak 10 orang purposive sampling. 2) Melaksanakan pre-test untuk mengetahui kemapuan awal power otot tungkai. 3) Hasil tes power otot tungkai diranking dari hasil tertinggi sampai hasil terendah. 4) Selanjutnya sampel diberikan perlakuan dengan latihan stride jump crossover dan latihan single eg stride jump. 5) Semua sampel melakukan latihan selama 6 minggu dalam 18 kali pertemuan dengan frekuensi latihan 3 kali seminggu. 6) Pada minggu ke 7 dilaksanakan post-test untuk mengetahui kemapuan power otot tungkai, setelah menjalani latihan stride jump cross over dan latihan single leg stride jump. 7) Setelah data pre-test dan data post test diperoleh, selanjutnya dilakukan perhitungan statistic uji-t untuk membuktikan hipotesis yang dikemukakan diterima atau ditolak.

\section{HASIL DAN PEMBAHASAN}

Berdasarkan data hasil pre-test dan post-test pada hasil power otot tungkai dengan menggunakan test vertical jump terdapat peningkatan dengan nilai rata-rata antara 32 dan 36,7, beda rata-rata 4,7 dan memiliki simpangan baku 4,81 dan 6,07, serta memiliki simpangan baku beda 11,56 sehingga di dapat ttabel 2,26 dan thitung 4,39 .

Pengujian normalitas data dengan menggunakan uji liliefors, dari kolom daftar pre-test latihan stride jump crossover dan latihan single leg stride jump terhadap power otot tungkai didapat Lo $=0,096$ dan $\mathrm{Lt}=0,258$ dengan $\mathrm{n}=10$ dan taraf nyata $\alpha=$ 0,05. Karena Lo $<$ Lt maka dapat disimpulkan bahwa sampel berasal dari populasi distribusi normal.

Pengujian normalitas data dengan menggunakan uji liliefors, dari kolom daftar post-test latihan stride jump crossover dan latihan single leg stride jump terhadap power otot tungkai didapat Lo $=0,2168$ dan $\mathrm{Lt}=0,258$ dengan $\mathrm{n}=10$ dan taraf nyata $\alpha=$ 0,05. Karena Lo $<\mathrm{Lt}$ maka dapat disimpulkan bahwa sampel berasal dari populasi distribusi normal.

Uji homogenitas data pre-test dan post test pada power otot tungkai didapat hasil perhitungan diatas harga Ftabel dengan 
Pengaruh Latihan Stride Jump Crossover Dan Latihan Single Leg Stride Jump Terhadap Power Otot Tungkai Atlet Bola Voli Putri Johar VC Deli Serdang Tahun 2020

taraf $\alpha=0,05$ dan $\mathrm{dk}$ pembilang $=10-1=9$ dan $\mathrm{dk}$ penyebut $=10-1=9$, dimana diperoleh Ftabel $(9,9)=3,18$ dengan demikian Fhitung $=1,60<$ Ftabel $=3,18$. Berarti Ho diterima. Kesimpulannya adalah data berasal dari varians yang homogeny.

Berdasarkan hasil perhitungan yang dilakukan maka diperoleh pengujian hipotesis Thitung sebesar 4,39. Selanjutnya harga tersebut dibandingkan dengan harga $\mathrm{t}_{\text {tabel }}$ dengan $\mathrm{dk}=\mathrm{n}-1=10-1=9$ pada taraf signifikan $\alpha=0,05=2,26$. Di dalam kriteria pengujian hipotesis dinyatakan bahwa pada thitung $>$ ttabel $(4,39>2,26)$ dengan $\alpha=0,05$ maka Ho ditolak dan Ha diterima. Maka dapat disimpulkan bahwa terdapat pengaruh yang signifikan dari latihan stride jump crossover dan latihan single leg stride jump terhadap power otot tungkai pada atlet bola voli putri Johar VC deli serdang tahun 2020.

Berdasarkan dari teori-teori yang telah dikemukakan pada kerangka teoritis, tampak jelas bahwa untuk menunjang suatu otot tungkai yang baik maka di perlukan fisik yang baik. Sebab adanya kondisi fisik yang baik maka dalam seorang atlet bola voli dengan mudah untuk melakukan teknikteknik apa saja dengan arah power yang dikehendakinya (Munandar, A., Taufik, M. S., \& Putri, R. E., 2020). Dalam permainan bola voli hampir seluruh gerakan didominasi oleh otot tungkai, dengan demikian pemain dituntut memiliki power otot tungkai yang baik. Dengan memiliki power otot tungkai yang baik diharapkan pemain bola voli dapat bermain dengan baik. Power otot tungkai memiliki peran yang sangat penting dalam permainan bola voli, salah satunya adalah dalam melakukan smash. Dalam melakukan smash power otot tungkai berperan untuk menghasilkan lompatan yang tinggi pada saat melakukan smash, sehingga kualitas smash yang dilakukan akan sulit untuk dibendung dan diantisipasi oleh lawan.

Untuk seorang atlet bola voli dituntut agar memiliki power otot tungkai yang baik sehingga dapat mendukung prestasi maksimal dalam bola voli (Eriyaldi, E., 2019). latihan stride jump crossover yang merupakan salah satu bentuk latihan plyometrics yang bertujuan untuk meningkatkan power otot tungkai. Pada latihan stride jump crossover otot tungkai dipacu untuk berkontraksi agar dapat melakukan gerakan melompat keatas box berkali-kali dengan tolakan kaki bergantian. Dengan demikian diharapkan dari latihan yang diterapkan dapat meningkatkan power otot tungkai.

Demikian dengan Latihan single leg stride jump merupakan satu bentuk latihan plyometrics yang bertujuan untuk 
Pengaruh Latihan Stride Jump Crossover Dan Latihan Single Leg Stride Jump Terhadap Power Otot Tungkai Atlet Bola Voli Putri Johar VC Deli Serdang Tahun 2020

meningkatkan power otot tungkai. Pada latihan single leg stride jump otot tungkai dipacu untuk berkontraksi agar dapat melakukan gerakan lompatan dengan ayunan ke atas. Dengan demikian diharapkan dari latihan yang diterapkan dapat meningkatkan power otot tungkai. Kedua bentuk latihan ini dapat meningkatkan power otot tungkai, karena pada bentuk latihan Stride Jump Crossover dan latihan Single Leg Stride Jump akan memberi rangsangan yang lebih besar, terutama power otot tungkai karena gerakan lompatan dilakukan dengan ayunan tangan dan dilakukan dengan satu kaki secara bergantian. Jika dilihat dari analisis gerak kedua bentuk latihan sama-sama memiliki karakteristik gerak yang sesuai dalam permainan bola voli.

\section{KESIMPULAN}

Berdasarkan hasil penelitian ditarik kesimpulan bahwa latihan stride jump crossover dan latihan single leg stride jump memberikan pengaruh yang signifikan terhadap power otot tungkai pada atlet bola Voli Putri Johar VC deli serdang tahun 2020.

\section{DAFTAR PUSTAKA}

Arif, Y., \& Alexander, X. F. R. (2019). Pengaruh latihan plyometric jump to box terhadap power otot tungkai pemain bola voli pada tim putri penjaskesrek undana. Jurnal segar, 8(1), 38-46.

Arrahman, Z. (2017). Pengaruh Latihan Depth Jump Terhadap daya Ledak Otot Tungkai Atlet Bolavoli. Jurnal Pendidikan Rokania, Sekolah Tinggi Keguruan Dan Ilmu Pendidikan (STKIP) Rokania, Rokan Hulu, Riau, 2(3), 322-332.

Eriyaldi, E. (2019). Pengaruh Latihan Plyometric Menggunakan Metode Circuit Terhadap Kemampuan Smash Atlet Bolavoli. Jurnal Patriot, 1(3), 1160-1168.

Hidayat, T., Saichudin, S., \& Kinanti, R. G. (2018). Pengaruh Latihan Plyometric Depth Jump dan Jump To Box Terhadap Power Otot Tungkai pada Pemain Ekstrakurikuler Bolavoli SMK Teknologi Nasional Malang. Jurnal Sport Science, 7(2), 136-143.

Mubarrok, M., \& Adi, S. (2017). Pengaruh Variasi Latihan Squat Terhadap Peningkatan Power Otot Tungkai pada Pemain Bolavoli Putri. Indonesia Performance Journal, 1(2), 125-129.

Munandar, A., Taufik, M. S., \& Putri, R. E. (2020). Pengaruh Latihan Plyometrics Otot Tungkai Terhadap Hasil Tendangan Penalti Pada Cabang Olahraga Futsal. Jurnal Maenpo: Jurnal Pendidikan Jasmani Kesehatan Dan Rekreasi, 10(1), 1-6.

Oktaviani, S. M. (2020). Pengaruh Latihan Plyometrics Terhadap Kemampuan 
Pengaruh Latihan Stride Jump Crossover Dan Latihan Single Leg Stride Jump Terhadap Power Otot Tungkai Atlet Bola Voli Putri Johar VC Deli Serdang Tahun 2020

Daya Ledak Otot Tungkai dan Kemampuan Smash Atlet Bolavoli SMAN $01 \quad$ Mukomuko. Jurnal Patriot, 2(2), 526-536.

Roziandy, M., \& Budiwanto, S. (2020). Pengaruh Latihan Naik Turun Bangku Terhadap Power Otot Tungkai pada Atlet Bolavoli Putri. Indonesia Performance Journal, 4(1), 36-40.

Sajoto, M. (1989). Pembinaan Kondisi Fisik dalam Olahraga. Jakarta : PT. Gramedia. 